Check for updates

Kent

Cite this as: BMJ 2021;374:n1797 http://dx.doi.org/10.1136/bmj.n1797 Published: 14 July 2021

\section{Covid-19: France and Greece make vaccination mandatory for healthcare workers}

\author{
Jacqui Wise
}

France and Greece have announced that vaccinations against SARS-CoV-2 will be mandatory for healthcare workers, but there seems to be little enthusiasm for the UK to go down that route.

The UK government said on 16 June that it would launch a public consultation "in due course" on whether to make vaccination against coronavirus and flu a condition of deployment in health and care settings. ${ }^{1}$ A Department of Health and Social Care spokesperson said, "This is a complex issue, and the government is looking for a wide range of perspectives from across the health and care sector about whether this should be introduced and how it could be implemented." But no date has yet been set for this to start.

It will, however, soon be mandatory for people working in care homes to be fully vaccinated against the coronavirus. From October-subject to parliamentary approval and a subsequent 16 week grace period-all people working in a Care Quality Commission registered care home in England for residents who require nursing or personal care must have two doses of a coronavirus vaccine unless they have a medical exemption.

On 12 July the French president, Emmanuel Macron, announced that mandatory vaccination would apply to anyone who comes into contact with vulnerable people, including doctors, nurses, office staff, and volunteers. $^{2}$ They must be fully vaccinated against the coronavirus by 15 September or will risk not being paid.

Macron added that from 21 July anyone wanting to visit a theatre, cinema, sports venue, or festival involving an audience of more than 50 people would need to show a pass proving that they were either fully vaccinated or had tested negative. From 1 August this requirement will extend to cafes, bars, restaurants, shopping malls, and long distance trains. After his announcement almost a million people, most of them under 35 , booked their vaccination.

\section{Delta variant}

As in much of Europe, the delta variant is causing cases to rise in France. The country now has more than 4000 cases a day, double last month's figure. On 11 July $52.6 \%$ of its total population had received at least one dose of the vaccine, and $36.8 \%$ were fully vaccinated. ${ }^{3}$

In Greece the prime minister, Kyriakos Mitsotakis, announced that nursing home staff needed to get vaccinated immediately, while healthcare workers would have to be vaccinated from 1 September. ${ }^{4}$
Italy was the first country in Europe to make vaccination for the covid pandemic mandatory for healthcare workers. ${ }^{5}$

Some countries are going even further. Turkmenistan is the first country to legally require all residents over 18 to be vaccinated against the coronavirus. Since March, Saudi Arabia has operated a broad "no jab, no job" policy in its public and private sectors. ${ }^{6}$

Data from NHS England show that $85 \%$ of healthcare workers (1 169080 of 1378 502) had received both doses of vaccine by 8 July, leaving 209422 not fully protected. That figure covers people directly employed by the NHS and does not include agency staff or NHS bank staff. ${ }^{7}$ In London the vaccination levels are lower at $76 \%$, with 46227 staff not fully vaccinated.

\section{Consent, not compulsion}

The NHS Confederation has said that the current approach of encouraging uptake through informed consent is the preferred option. The BMA is also calling for targeted engagement and possible alternative mitigations against transmission for people who are not vaccinated. Chaand Nagpaul, BMA council chair, called compulsion "a blunt instrument to tackle a complex issue.”

Peter English, former editor of Vaccines in Practice and immediate past chair of the BMA's public health committee, told The BMJ, "The problem with making things mandatory is that it often creates a backlash, and you can get more people refusing to have the vaccine because they are being forced to. The general view is that mandatory vaccination should be a last resort."

Some frontline healthcare workers already need to be immunised to work in certain areas, for example against hepatitis B, or must show that they are not infectious with other diseases. However, this is not the law but rather hospital trusts enacting policies on workplace health and safety and occupational health. General Medical Council guidance states that doctors should be immunised against common serious communicable diseases unless this is contraindicated. ${ }^{8}$

Jonathan Ives, associate professor in empirical bioethics at Bristol Medical School, told The BMJ, "There is an age old clash between respecting autonomy and restricting liberty for public or individual safety. We tend to accept in principle that we can restrict certain liberties for the greater good-for example, mandatory seatbelts in cars. The big question is where we draw that line."

He said that if vaccination is required for a person to go to the cinema or a restaurant, for example, people 
may choose not to do it and their life will not be seriously affected. If healthcare workers have to have the vaccine or face losing their job, however, this is less of a real choice. "The more coercive it is, the more ethically problematic it becomes,” said Ives.

He added, "I personally support vaccination, but if we can move healthcare workers who refuse the vaccine, for whatever reason, into other areas where they can work safely without it, that has to be preferable to mandatory vaccination. A nuanced and flexible approach has to be the first port of call, with coercive measures a last-and temporary-resort."

1 Department of Health and Social Care. Everyone working in care homes to be fully vaccinated under new law to protect residents. 16 Jun 2021. https://www.gov.uk/government/news/everyoneworking-in-care-homes-to-be-fully-vaccinated-under-new-law-to-protect-residents

2 France covid: vaccinations mandatory for all health workers. BBC News 2021 Jul 13. https://www.bbc.co.uk/news/world-europe-57814163

3 Share of the population fully vaccinated against covid-19. Our World in Data. 13 Jul 2021. https://ourworldindata.org/grapher/share-people-fully-vaccinated-covid

4 Greece orders covid-19 vaccinations as infections rise. Reuters 2021 Jul 12.

https://www.reuters.com/world/europe/greece-rolls-out-covid-19-vaccinations-those-aged-1517-2021-07-12/

5 Paterlini M. Covid-19: Italy makes vaccination mandatory for healthcare workers. BMJ 2021;373:n905. doi: 10.1136/bmj.n905 pmid: 33824155

6 Dyer 0. Covid-19: Turkmenistan becomes first country to make vaccination mandatory for all adults. BMJ 2021;374:n1766. doi: 10.1136/bmj.n1766 pmid: 34253537

7 NHS England. Covid-19 vaccinations. https://www.england.nhs.uk/statistics/statistical-work-areas/covid-19-vaccinations/

8 General Medical Council. Good medical practice-Domain 2: Safety and quality. https://www.gmcuk.org/ethical-guidance/ethical-guidance-for-doctors/good-medical-practice/domain-2----safetyand-quality\#paragraph-29

This article is made freely available for use in accordance with BMJ's website terms and conditions for the duration of the covid-19 pandemic or until otherwise determined by BMJ. You may use, download and print the article for any lawful, non-commercial purpose (including text and data mining) provided that all copyright notices and trade marks are retained. 